\title{
Impact of lockdown during COVID-19 pandemic on annual effective dose equivalent values of natural gamma radiation
}

\author{
Manoj Kumar Jindal ${ }^{1}$ (D) Santosh Kumar Sar ${ }^{1}$
}

Received: 18 July 2020 / Accepted: 26 September 2020 / Published online: 12 October 2020

(c) Akadémiai Kiadó, Budapest, Hungary 2020

\begin{abstract}
The study aimed to determine the impact of COVID-19 on values of annual effective dose equivalent of the natural gamma dose rate of Balod, Durg and Bemetara districts of Chhattisgarh (India). COVID-19 is a severe problem for many countries and to control and prevent the spread of this problem, the lockdown approach has been implemented in many countries, including India. In this lockdown situation, almost all people stay at home for $24 \mathrm{~h}$. Due to the present status of COVID-19, the Indian government also fixed the 67 days lockdown and one day was already successfully done as Janta Curfew, which worked the same as a lockdown. The value of indoor gamma dose rates was reported to be higher in most places compared to the outdoor gamma dose rate, but in this pandemic situation, occupancy factor values are not applicable as recommended by UNSCEAR for calculation of annual effective dose equivalent (AEDE). Therefore, the present study introduces the new equations, which can measure the extra AEDE value during lockdown for adults, children and infants.
\end{abstract}

Keywords Annual effective dose equivalent $\cdot$ Lockdown $\cdot$ COVID-19 - Gamma dose rate $\cdot$ Chhattisgarh region

\section{Introduction}

COVID-19 due to Coronavirus is distressing many countries and their territories around the world [1,2]. This pandemic emerged during December 2019 from Wuhan city of China to other parts of the world [3]. In this problematic situation, every country is working on applying many strategies to prevent and control the spread of coronavirus among their people. Many countries already applied tremendous strategies, which include one of the dominant strategies is lockdown of state or country. The Indian government has also adopted this strategy and before applying lockdown, the prime minister of India has requested the Indian public to follow selflockdown as called Janta Curfew for one day (22 March 2020), which was efficacious. The Indian government has declared a total of 21 days (from 24 March 2020 to 14 April 2020) as a lockdown, which extended three times from 15 April 2020 to 3 May 2020; 4 May 2020 to 17 May 2020 and 18 May 2020 to 31 May 2020 [4]. The annual effective dose of gamma radiation is the most important value to estimate

Manoj Kumar Jindal

manojjindal1989@gmail.com

1 Department of Applied Chemistry, Bhilai Institute of Technology, Durg, India the effect of gamma radiation on mankind, UNSCEAR was given the formula for calculation of these values and this formula is utilized around the world for estimation of AEDE values [5]. The annual effective dose is calculated by using indoor and outdoor gamma dose and based on many studies, indoor gamma dose rate values are usually higher than the outdoor gamma dose rate, except in a few countries or territories of the world $[5,6]$. Lockdown situations where movement restricted will affect the AEDE values because, in this period, the public stays inside of the house instead of outside. Hence, the values of the annual gamma dose rate will change in the lockdown period. The intention of this study was to estimate the extra AEDE value of the natural background gamma dose rate during this lockdown period for adults, children and infants from areas (Balod, Durg and Bemetara) of the Chhattisgarh region.

\section{Material and methodology}

All researchers usually used the formulas for calculation of AEDE value, which were reported by UNSCEAR by applying the indoor and outdoor gamma dose rate, which was as $[5,7]$ : 
$A E D E($ indoor $/$ outdoor $)=D($ indoor $/$ outdoor $)$

$$
\begin{aligned}
& \times T \times \text { conversion coefficient } \\
& \times \text { occupancy factor }
\end{aligned}
$$

where $D_{\text {(indoor) }}=$ Indoor absorbed gamma dose rate $(\mathrm{nGy} / \mathrm{h}) . D_{\text {(outdoor) }}=$ Outdoor absorbed gamma dose rate $(\mathrm{nGy} / \mathrm{h}) . T=$ Time conversion factor (hour into a year) $(1$ year $=8760 \mathrm{~h})$.

The dose conversion coefficient value for an adult was 0.7 (UNSCEAR), and the values of the occupancy factor for outdoor and indoor were 0.2 and 0.8 , respectively [5]. The conversion coefficient values for the children and infants were approximately 10 and 30\% higher than those for adults [5]. The value of the total AEDE value was calculated by the accumulation of the AEDE values of indoor and outdoor gamma dose rates.

In India (including all states), 68 days set for lockdown means people of the country will be spending $1632 \mathrm{~h}$ inside of houses. It indicated that out of $8670 \mathrm{~h}$ in a year, people utilize $1632 \mathrm{~h}$ inside of houses. Moreover, the remaining hours of the year $7128 \mathrm{~h}$ can be utilized as the normal distribution of occupancy factors of 0.8 and 0.2 for indoor and outdoor. As of now (18 July 2020), the COVID-19 condition is still continuing $[1,4]$. The lockdown of the few places of Chhattisgarh State might be increased by the central government of India or state government of Chhattisgarh. The Indian government has declared June and July month as unlock-1 and unlock-2 means all work will start slowly but still education or few other organizations such as schools, colleges closed.

\section{Results and discussion}

The annual effective dose values were already published by many researchers and in our previous studies [6-9]. Table 1 shows the calculation of extra annual effective dose values by using Balod, Durg and Bemetara districts indoor and outdoor gamma dose rate values [6-9]. In columns, D and E present the AEDE values of indoor and outdoor, respectively, by using the $7128 \mathrm{~h}$ after subtracting the $1632 \mathrm{~h}$ of lockdown (period of lockdown) [4]. The F column indicates the AEDE value during lockdown and the addition of D, E and $\mathrm{F}$ is the total AEDE value with 68 days of lockdown. Annual effective dose values were also calculated by using Eq. 1 with occupancy factors of 0.8 and 0.2 for indoor and outdoor respectively, and these values were subtracted from lockdown values to obtain the total extra dose, which can be received by people during the lockdown period, which was precisely the same as calculated. The same value can be calculated directly by using the following formula.
Extra AEDE value during lockdown for adult

$$
=\left[(X \times 228)+\left\{(-2.42) \times e^{-11}\right\}\right]
$$

Extra AEDE value during lockdown for children

$$
=\left[(X \times 261)+\left\{(-3.78) \times e^{-11}\right\}\right]
$$

Extra AEDE value during lockdown for infants

$$
=\left[(X \times 294)+\left\{(-3.02) \times e^{-11}\right\}\right]
$$

where $X=$ difference between indoor and outdoor gamma dose rate.

The range of difference between indoor and outdoor gamma dose rates was found from -20 to $124 \mathrm{nSv} / \mathrm{h}$. These difference values were used to calculate the extra annual dose rate during the lockdown period for adults, children and infants. The resultant values showed a strong correlation between indoor and outdoor gamma dose rates. The relation between both can be calculated by using Eqs. 3, 4 and 5 for adults, children and infants, respectively. The relationship between extra gamma dose rate values during lockdown and differences in indoor-outdoor gamma dose rate are shown in Figs. 1, 2 and 3 for adults, children and infants, respectively. The extra dose rate ranged from -4.57 to $28.33 \mu \mathrm{Sv} / \mathrm{y}$; -5.22 to $32.38 \mu \mathrm{Sv} / \mathrm{y}$ and -5.88 to 36.43 $\mu \mathrm{Sv} / \mathrm{y}$ for adults, children and infants, respectively.

\section{Conclusions}

- It has been observed that the calculation of extra AEDE values through Eq. 2 is the same as calculated by using AEDE separately; hence, it is suitable for estimation of additional natural gamma dose rate values during lockdown situations.

- This study will be helpful in calculating the extra annual effective dose value, and the mean values of extra AEDE for Balod, Durg and Beemetara districts of India were $10.66 \mu \mathrm{Sv} / \mathrm{y}, 12.18 \mu \mathrm{Sv} / \mathrm{y}$ and $13.70 \mu \mathrm{Sv} / \mathrm{y}$ for adults, children and infants, respectively.

- This study will be applicable in lockdown situations only, and formula (Eqs. 3, 4, 5) can be used for the estimation of extra AEDE values of natural gamma dose in many countries during 2020 due to COVID-19.

- The value of AEDE due to lockdown have been obtained highest and lowest 28,332 nSv/y and $-4570 \mathrm{nSv} / \mathrm{y}$ respectively at area Bortara (Bemetara district) and Piparchhedi (Balod district).

Extra AEDE value during lockdown $=D($ indoor - outdoor $) \times$ Time of lockdown

$\times$ conversion coefficient $\times$ difference in occupancy factor 


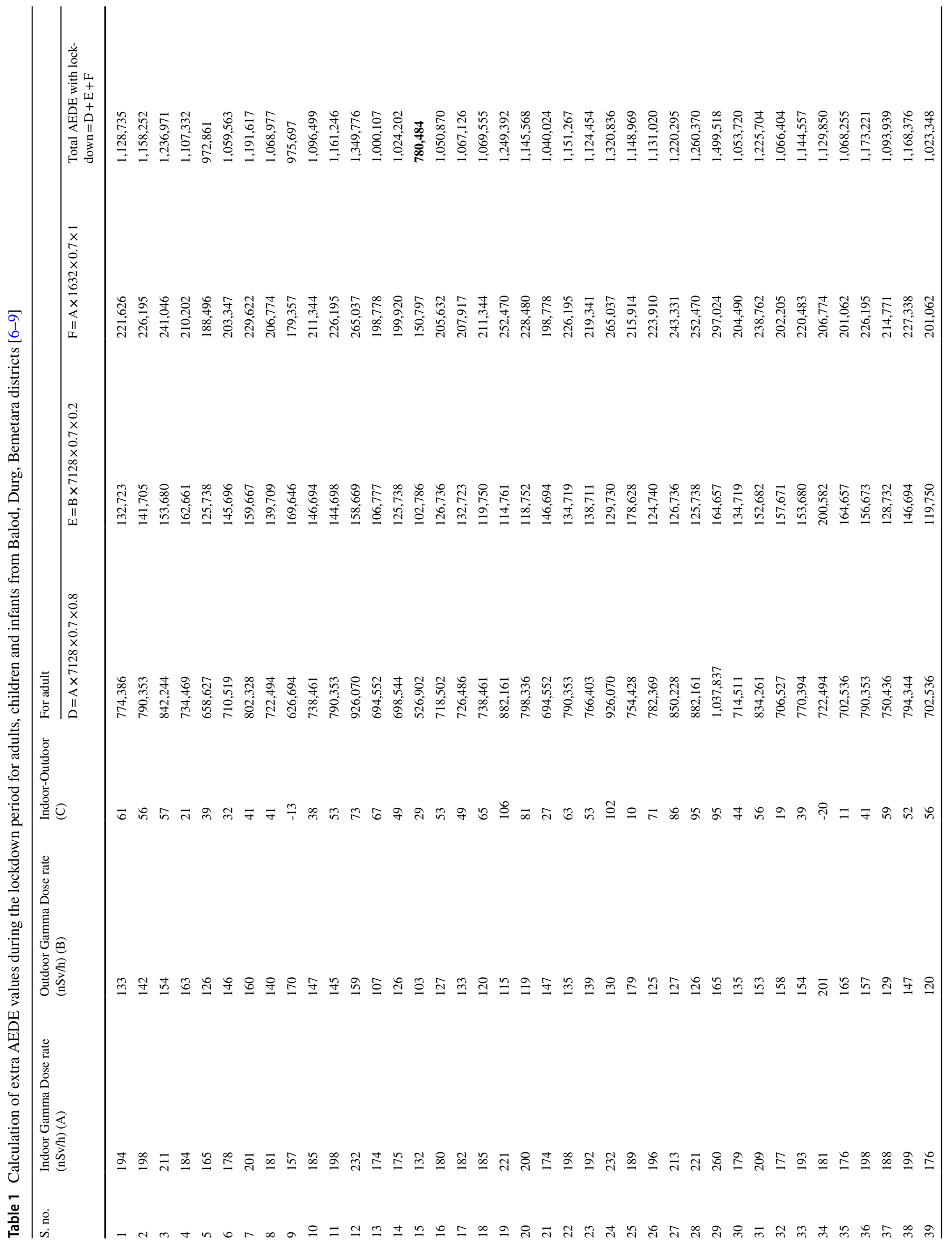




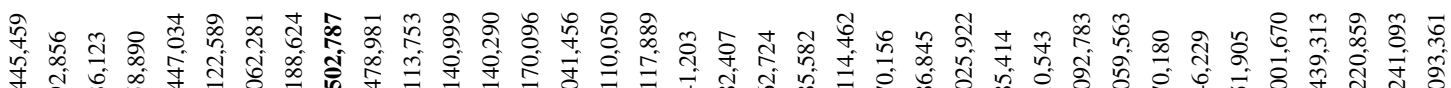

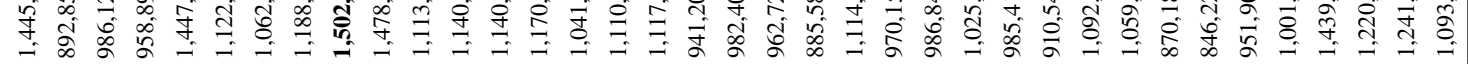

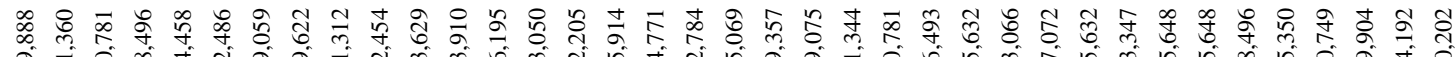
ปे

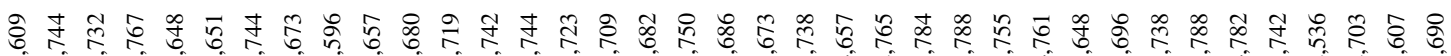
宑

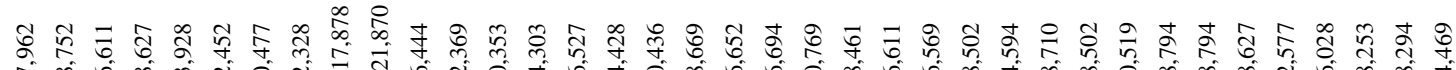

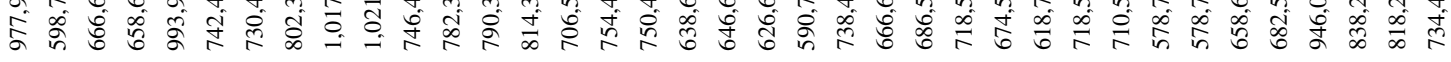
苞

$\frac{1}{10}$

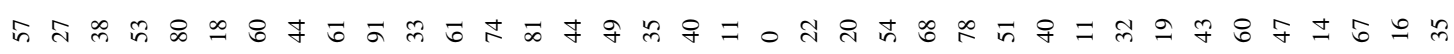
密

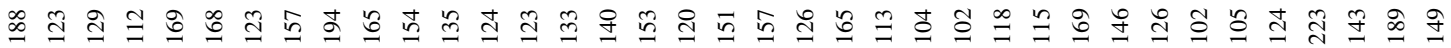




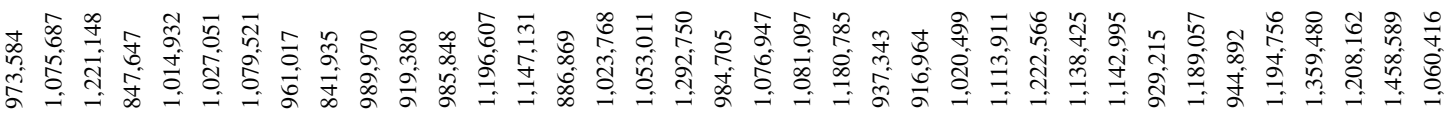

क

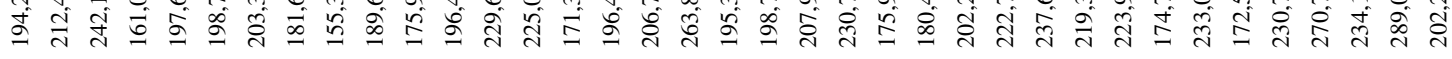

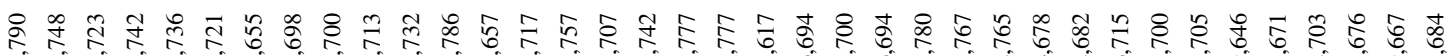

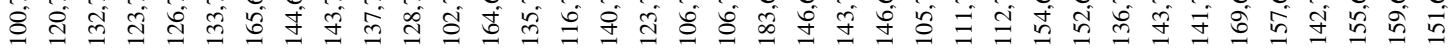

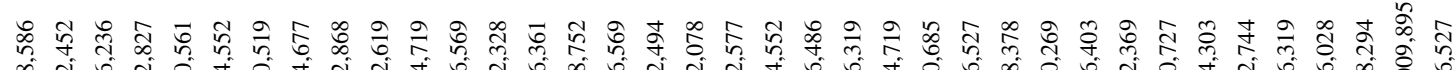

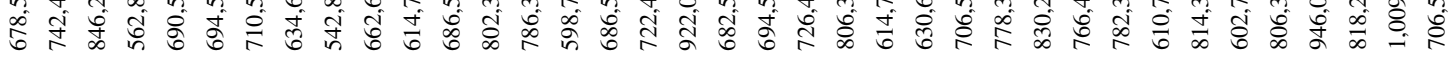
ᄒ

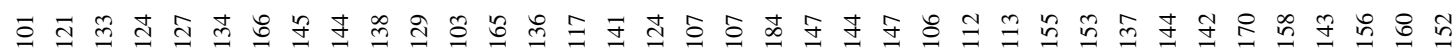

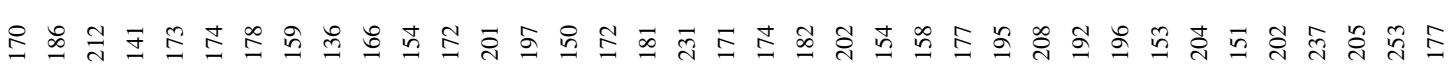

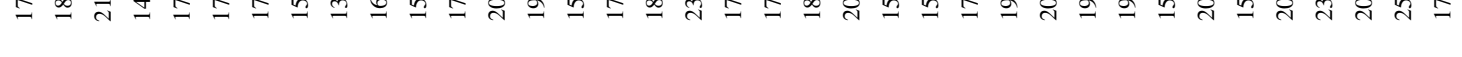




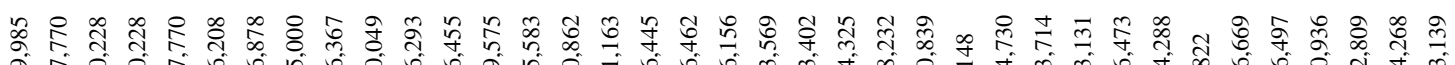
đิ

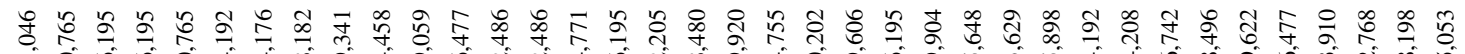

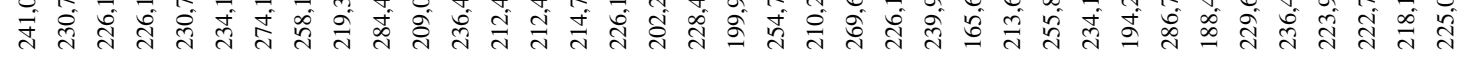

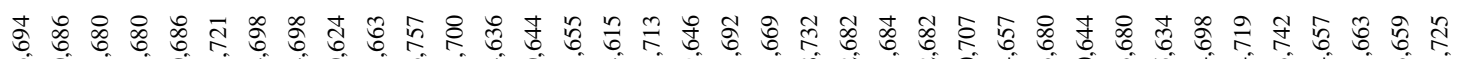

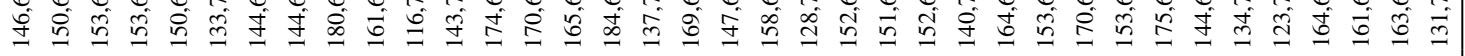

击

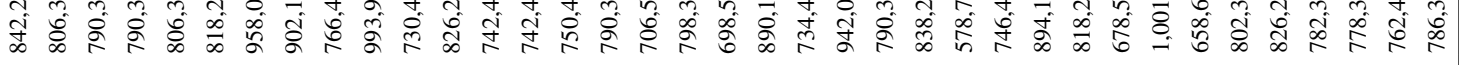
范 言

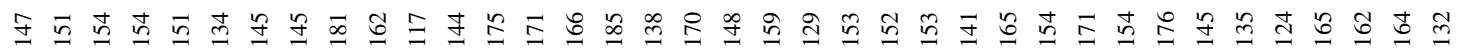

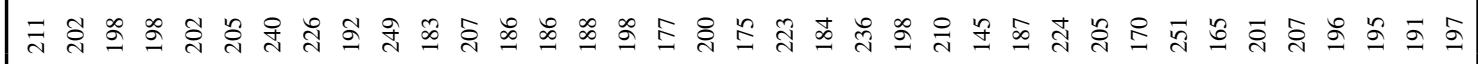
莺氮 包气 


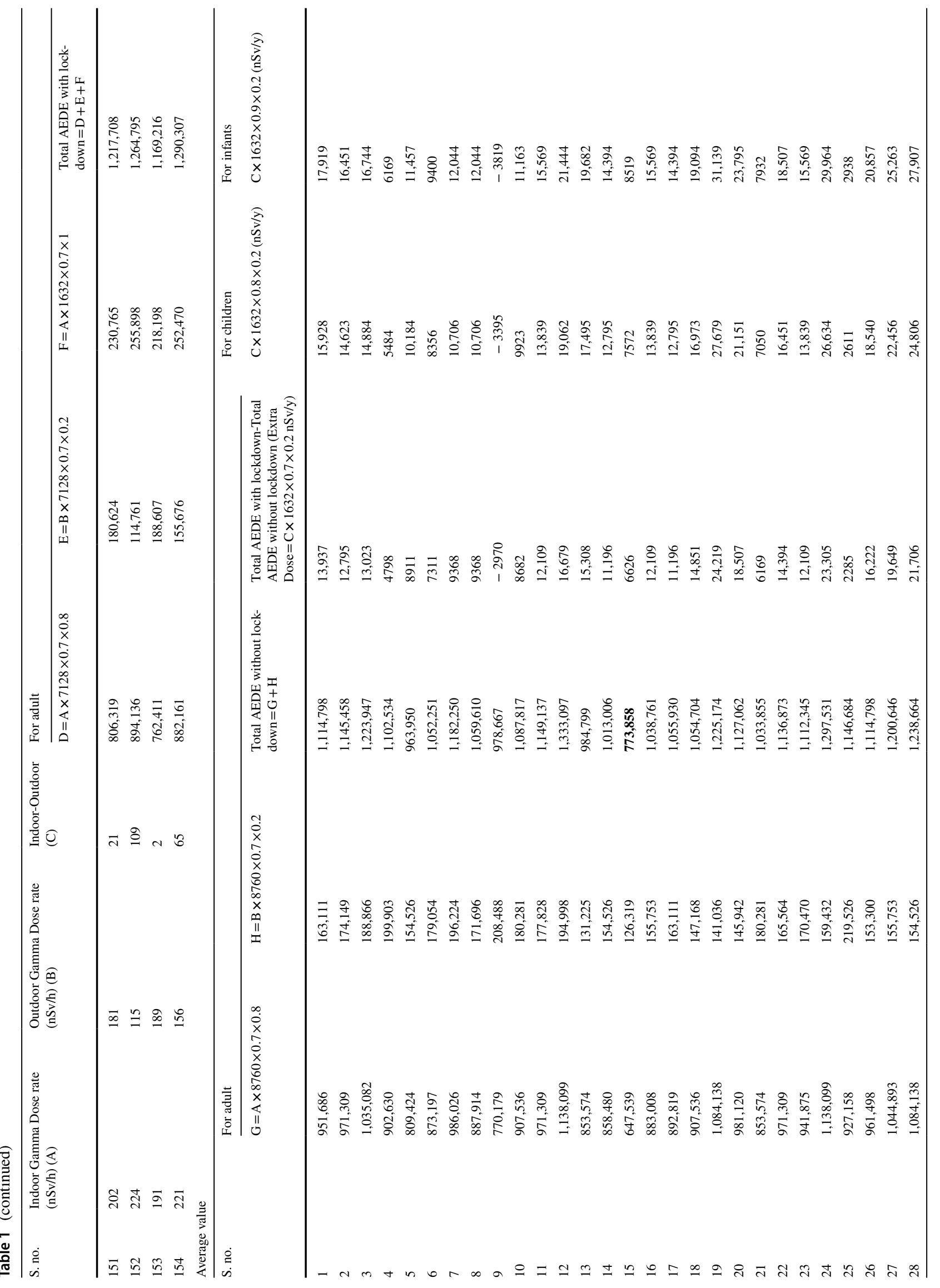




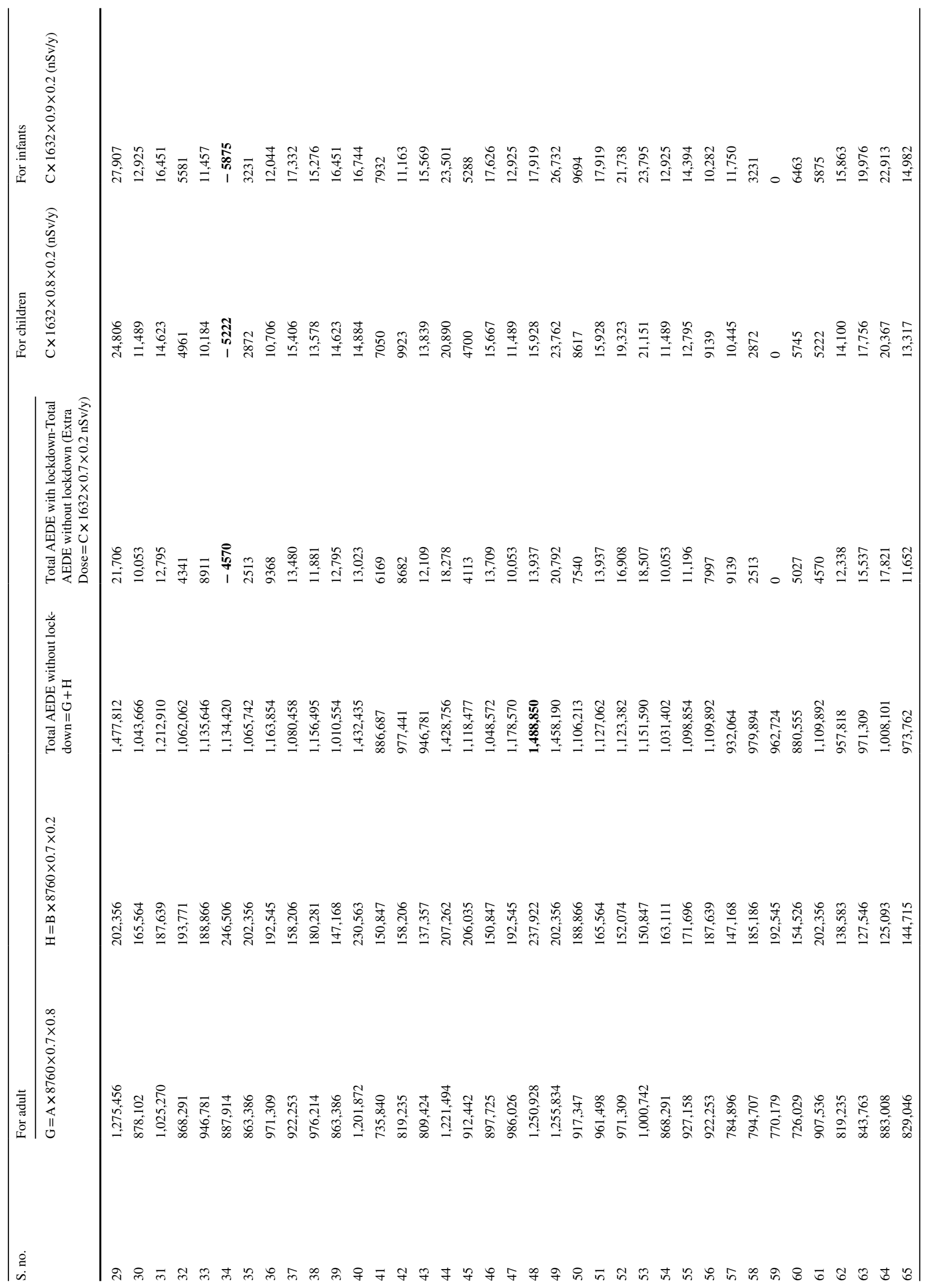




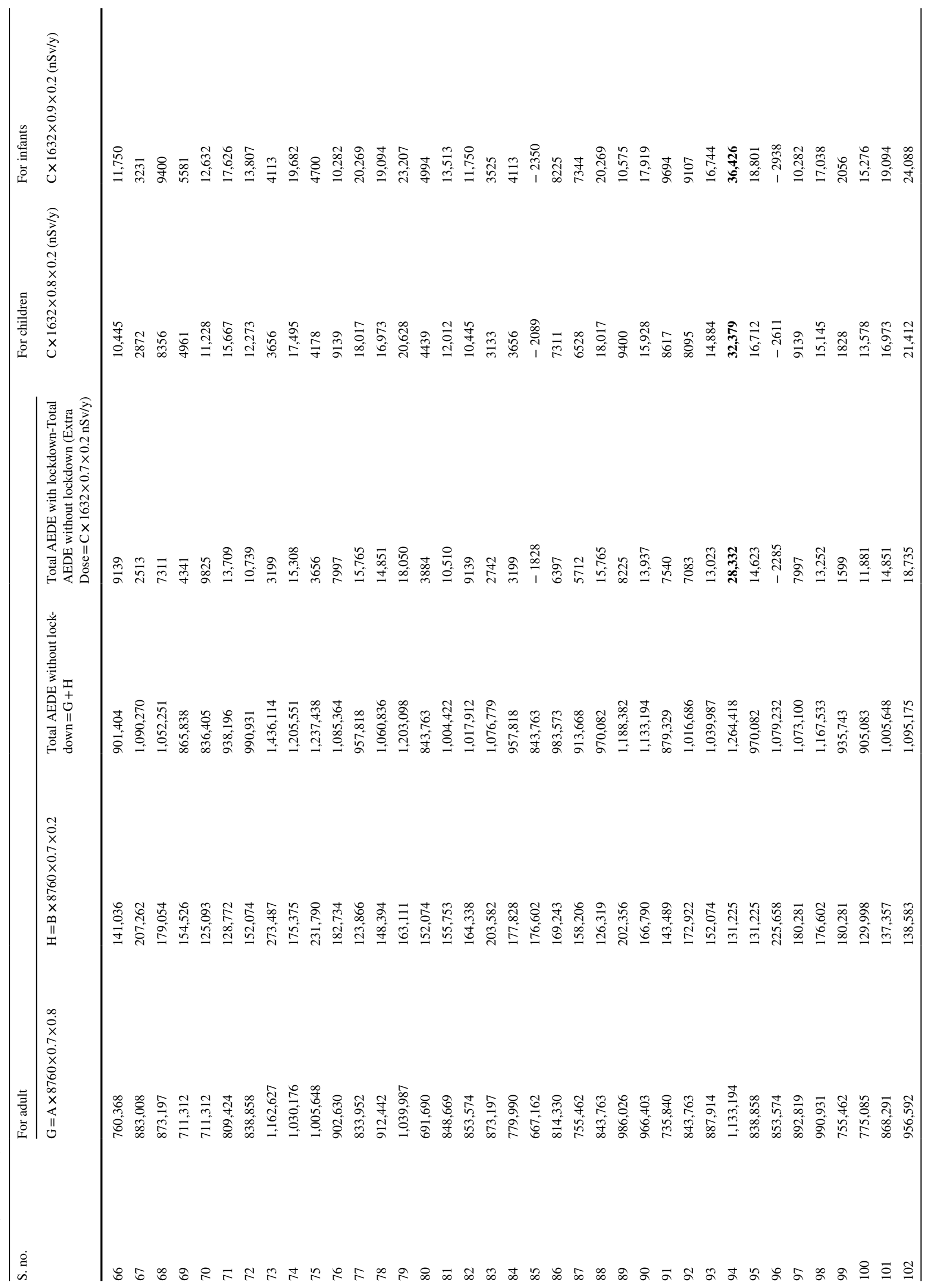




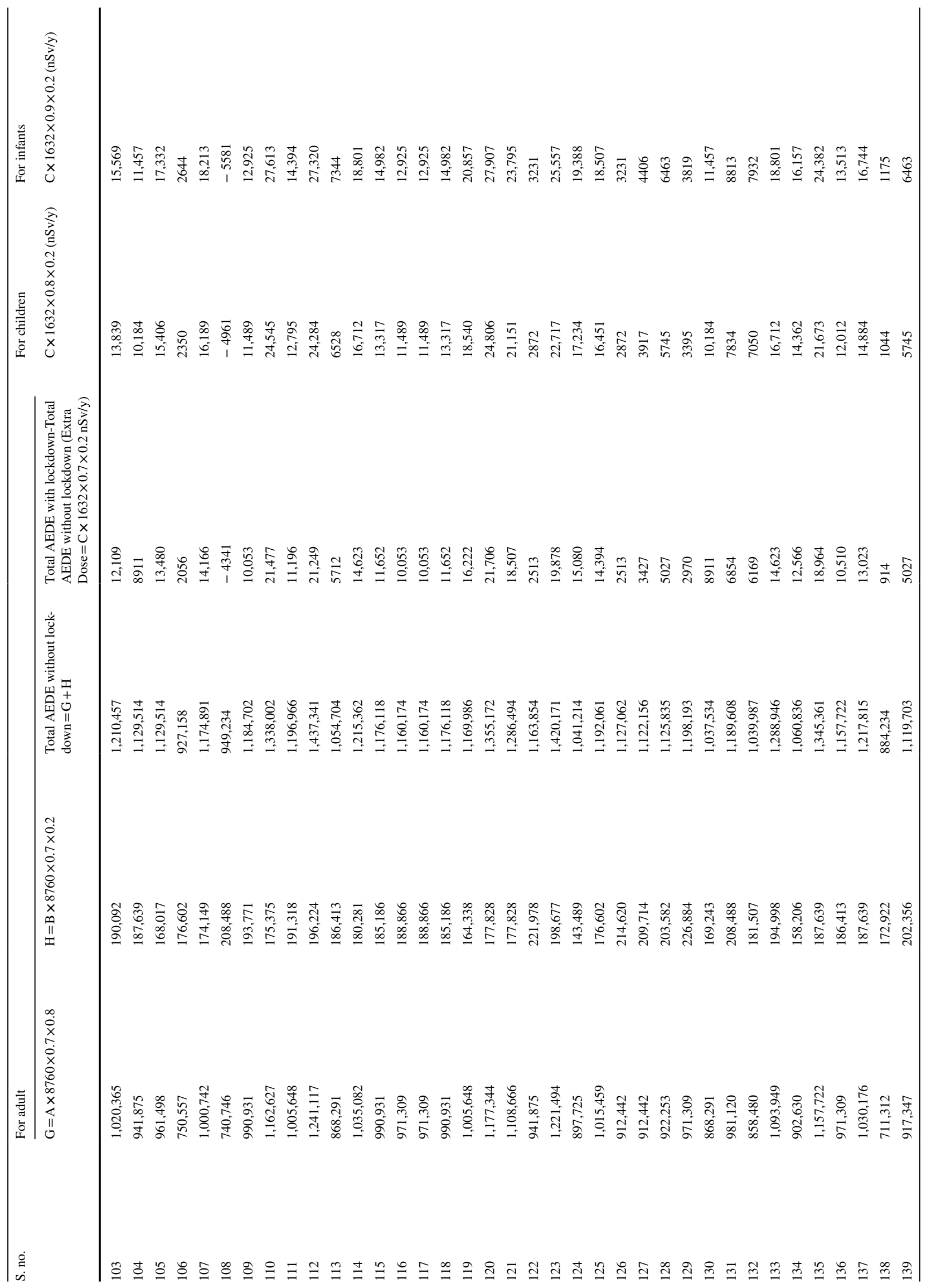




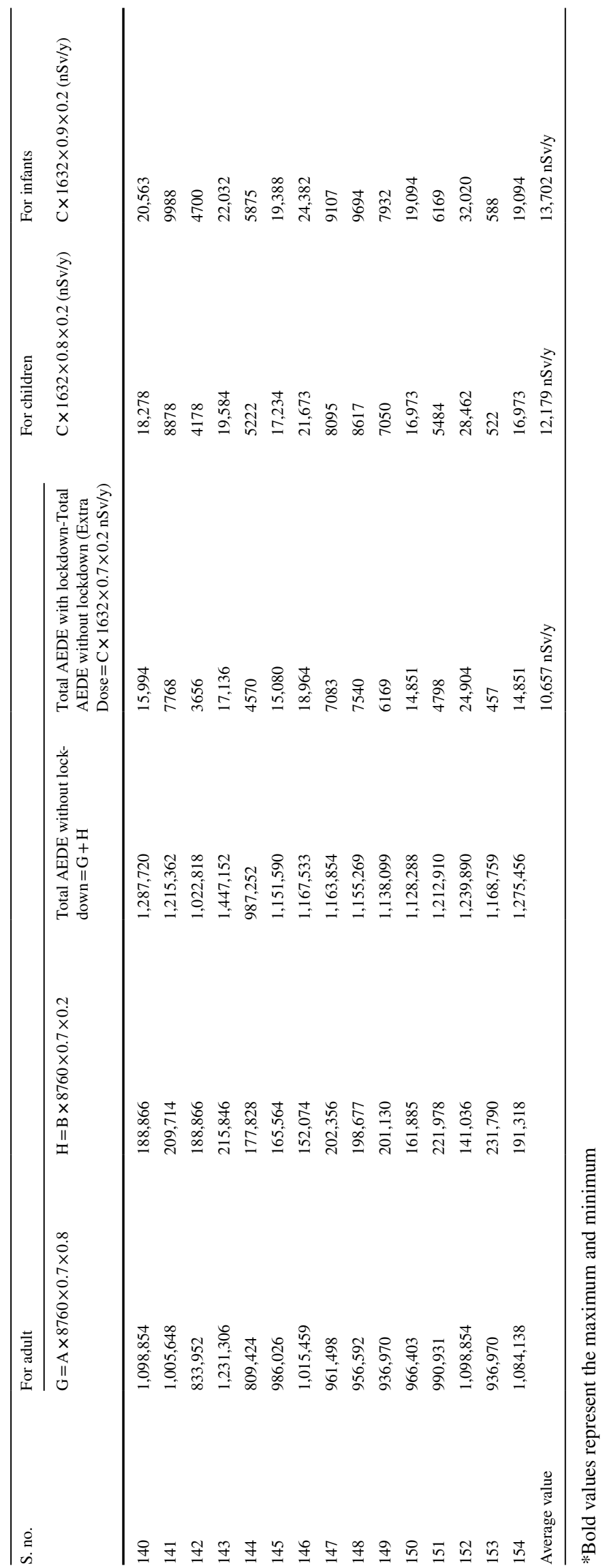


Fig. 1 Relationship between extra gamma dose rate values during lockdown and difference values of indoor-outdoor gamma dose rate for adults

\section{Extra dose rate for adult (nSv/y) vs. Indoor-Outdoor gamma dose rate \\ Extra dose rate for adult (nSv/y) $-228^{*} x+-2.42 E-11$}

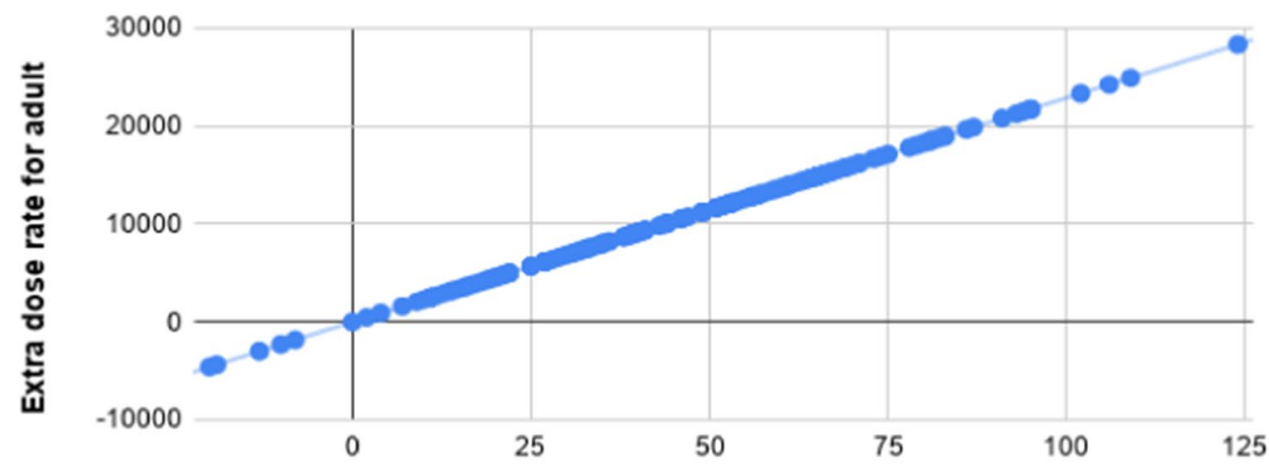

Indoor-Outdoor gamma dose rate

- During COVID-19, most of the people are inside the shelter, so the scenario of radiations upon outside and inside are drastically varied. Due to population, it varies somewhere low and high; however, geology and civil structure may be one cause of this variation.

- The range of relative difference in lockdown versus non-lockdown AEDEs varies from - 0.46 to $2.24 \%$ ( -4570 to $28,332 \mathrm{nSv} / \mathrm{y}$, absolute difference). The impact of lockdown appears inconsequential because the variability across the locations studied has a $48 \%$ relative difference in non-lockdown AEDE values $(773,858-1,488,850 \mathrm{nSv} / \mathrm{y})$ and lockdown AEDE values $(780,484-1,502,787 \mathrm{nSv} / \mathrm{y})$. In other words, while the lockdown produces a small difference in AEDE, the total effect is small compared to the variability in AEDE.

- This study will be beneficial for mankind to predict the annual gamma dose rate during the pandemic situation.
Fig. 2 Relationship between extra gamma dose rate values during lockdown and difference values of indoor-outdoor gamma dose rate for children

\section{Extra dose rate for children (nSv/y) vs. Indoor-Outdoor gamma dose rate}

Extra dose rate for child (nSv/y) $-261^{*} x+-3.78 E-11$

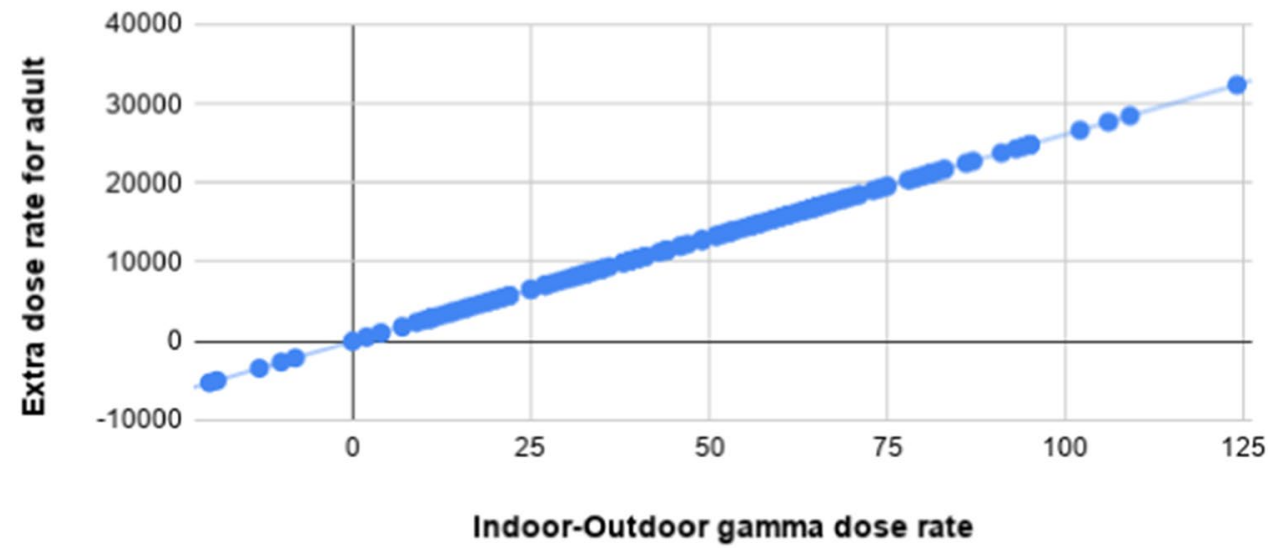


Fig. 3 Relationship between extra gamma dose rate values during lockdown and difference values of indoor-outdoor gamma dose rate for infants

\section{Extra dose rate for infants (nSv/y) vs. Indoor-Outdoor gamma dose rate}

Extra dose rate for infants (nSv/y) $=294^{*} \mathrm{x}+-3.02 \mathrm{E}-11$

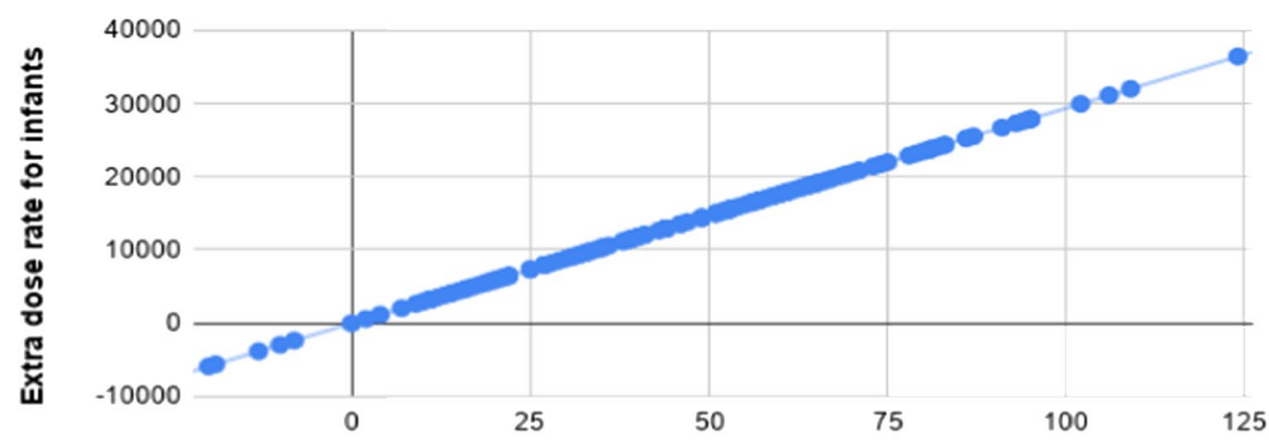

Indoor-Outdoor gamma dose rate

\section{Compliance with ethical standards}

Conflict of interest The authors declare that they have no conflict of interest.

\section{References}

1. Coronavirus disease (COVID-2019) situation reports. https:// www.who.int/emergencies/diseases/novel-coronavirus-2019. Accessed 10 July 2020

2. Worldometer. https://www.worldometers.info/coronaviru s. Accessed 18 July 2020

3. Mackenzie JS, Smith DW (2020) COVID-19: a novel zoonotic disease caused by a coronavirus from China: what we know and what we don't. Microbiology Australia. https://doi.org/10.1071/ MA20013

4. National Portal of India. https://www.india.gov.in and https:// www.mygov.in/covid-19. Accessed 10 July 2020
5. UNSCEAR (United Nation Scientific Committee on the effect of Atomic Radiations) (2000) Ionizing radiation. Sources and biological effects report to the general assembly with scientific annexes. United Nations, New York

6. Jindal MK, Sar SK (2020) Blueprint of indoor gamma dose rate through statistical modelling for Kabirdham district. J Radioanal Nucl Chem 325:121-131. DOI https://doi.org/10.1007/ s10967-020-07205-6

7. Jindal MK, Sar SK, Singh S, Arora A (2018) Risk assessment from gamma dose rate in Balod District of Chhattisgarh, India. J Radioanal Nucl Chem 317(1):387-395. https://doi.org/10.1007/ s10967-018-5846-9

8. Jindal MK, Sar SK, Arun A, Singh S, Sahu M, Diwan V (2018) Annual effective dose equivalent of population staying in industrial area Bhilai, Chhattisgarh India estimated using Gamma dose rate measurements. Res J Chem Environ 22(12):22-27

9. Jindal MK, Sar SK (2020) Statistical comparative study of the gamma dose rate and associated risk assessment in rural and urban areas of durg District,\&nbsp;Chhattisgarh, India. Radiochemistry 62(2):275-287. https://doi.org/10.1134/S1066362220020186

Publisher's Note Springer Nature remains neutral with regard to jurisdictional claims in published maps and institutional affiliations. 